\title{
Independent Review of ICI User Skills
}

Baroness Estelle Morris

June 2009 


\section{Contents}

Foreword

Section 1

Executive summary

Section 2

Introduction

\section{Section 3}

A definition of Digital Life Skills

Digital Life Skills definitions in summary

\section{Section 4}

The case for Digital Life Skills

The case for Digital Life Skills in summary

\section{Section 5}

The story so far: government policy 1997-2009

1997-2009 government policy digital agenda

2003-2009 government policy standards and qualifications

Government policy - in summary
4 Section 6

Existing provision of

6 Digital Life Skills

Providers

8

Trends in the volume of provision

23

Current sources of funding 26

9

Standards, qualifications and

27

9 Delivery of Digital Life Skills

Digital Life Skills 29

Existing provision of Digital

Life Skills - in summary

10

13

Section 7

Analysis of current policy

\section{Section 8}

Who are the digitally excluded?

Who are the digitally excluded in summary

\section{Section 9}

The way forward

In summary 


\section{Foreword}

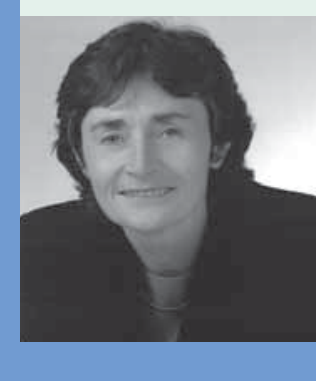

We've always known the consequences for adults who lack basic literacy and numeracy skills; we need to better understand the impact on those who lack basic ICT skills.

It's hard to imagine that, in little more than a decade, knowledge that used to be restricted to a small group of enthusiasts should have become an essential life skill. Yet ICT is fast becoming exactly that and we need to be certain that we are doing as much as we can to make sure everyone has the chance to develop the skills they need.

The importance of ICT skills to the economy and in employment is well known; the role it plays in access to information and services, leisure, health and social networking for all ages is perhaps less well understood. We expect the young to have these skills yet we tolerate those who are older never having the same opportunity. If we are to reduce social exclusion in society we must close the gap between the ICT-haves and have-nots.

I was pleased to be asked by Rt. Hon John Denham, Secretary Of State for Innovation, Universities and Skills to review government policy in adult basic ICT skills. In the last decade the number of adults who are online has increased from 8.1 million to 33.4 million. Yet 11 million adults in England are still ICT illiterate and meeting their needs is a considerable challenge.

It is right then to look at where we are, what has been successful and what could bring faster progress. The policy area now spans a number of government departments and it is also important to question whether that is the most appropriate structure for delivering this part of the wider ICT agenda.

My role was to provide an external voice, able to question why we are doing what we are doing and challenging existing policies.

This report recognises and applauds the work that has been done but concludes that in responding to this agenda existing policies and the government machinery have become too complicated and unwieldy. The report recommends a single focused strategy that brings together partners from media and business, retail and leisure, as well as government, all of whom have an interest in a truly digital Britain. 
We must all realise that if we allow the gap in ICT skills to continue we risk adding to the social and economic divides that already cause so much concern. Yet given the progress that has been made in the last decade, there must be a sense of optimism that we can get this right.

I am extremely grateful to the many stakeholders and partners who have generously given their time and advice to help inform this review. I would like to particularly recognise the support I have received from Michelle Lofthouse and Lucy Tanner to help me research and write the report.

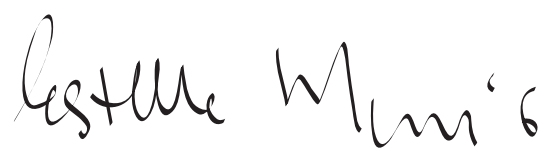

Estelle Morris 


\section{Section 1}

\section{Executive summary}

1. Commissioned by John Denham, the then Secretary of State for the Department of Innovation, Universities and Skills, this review seeks to consider the extent to which current policies are meeting the need for basic ICT skills in England.

2. The report adopts the term 'Digital Life Skills' to identify the set of basic ICT skills an adult will require to take their first steps online - using a computer to safely enter, access and communicate information.

3. The report outlines why Digital Life Skills have an important role to play in the health and wellbeing of UK citizens and the wider UK economy. In summary:

- digital skills have an impact on an adult's equality of access to information and services; employability; social inclusion, engagement in further learning, and on wider business productivity.

4. The review has been informed by the evaluation of detailed research into Digital Inclusion and has concluded that although the numbers of digitally excluded adults have reduced over time, to an estimated $11.6 \mathrm{~m}$ adults in England in 2008, the digital divide is widening for those most at risk: those adults over 65 , socially excluded, or with few or no qualifications.

5. The review has considered the impact of government policy on Digital Life Skills and concluded that, despite a number of successful projects and initiatives, we do not currently have a focused strategy to address the digital skills' gaps that have been identified.

6. In considering existing provision of basic ICT, the review noted:

- a $50 \%$ reduction in the number of adults taking up funded ICT provision since 2004/05, largely as a result of shorter courses being displaced by longer qualification-bearing provision.

- the complexity of the current system of different providers, funding routes and qualification outcomes which makes it hard for an adult to access the skills they need to get online. 
7. In recommending how best to address the Digital Life Skills needs of adults in England, the review proposes an 'Entitlement' to Digital Life Skills for all adults made up of:

- a social marketing campaign, driven through the Government's Digital Britain strategy, to highlight the benefits of getting online.

- a single helpline and website with online learning modules, with links to a range of free resources, provided by broadcasters and other commercial suppliers.

- access to a diverse range of entitlement providers to receive support to learn the basic skills they need to get online.

8. It is recognised that this review has been undertaken against a difficult economic backdrop where funding for skills is under pressure. This is reflected by a set of recommendations which seek to join up existing government funds and initiatives to promote and deliver this Entitlement. 


\section{Section 2}

\section{Introduction}

"We need to build the awareness of the benefits of internet technology to enhance the life chances of all. Otherwise inequality in the use and application of digital technologies is potentially a significant new driver of social exclusion in the 21st century, which risks accelerating existing social divides and creating new ones." (Digital Britain', 2009)

The digital landscape has been transformed over the last decade. Businesses, public services, individuals and families all use computers; online facilities have shaped the way our economy is run and the way we live our lives. Our young people have grown up as digital natives and millions of adults have now joined them.

It is a story of technological advance and rapid change; of government investment and public- and private-sector partnerships. We all know that the pace of change will not slow down.

Although the number of people who lack basic skills has reduced, there still remains a significant percentage of the population who are not part of this revolution. They lack the basic skills to access ICT and are at risk of being left further behind in a world that becomes ever more digital.

This report sets out to look at the progress that has been made in enabling everyone to develop Digital Life Skills; the extent of the challenge that remains; and to provide recommendations on how we might move forward to meet it.

The review focuses on England, but much of the research is UK-based and the actions identified may be equally applicable to the devolved administrations in Wales, Scotland and Northern Ireland. 


\section{Section 3 \\ A definition of Digital Life Skills}

The review concentrates on 'ICT basic skills for adults'. There are many terms used to describe these skills, a large number of which relate to qualification labels eg, ICT Skills for Life; ICT Key Skills and ICT Functional Skills.

The Interim Digital Britain Report, published by the Department for Business, Enterprise, and Regulatory Reform in January 2009, used the term 'Digital Life Skills' and we also use this term to refer to those skills an adult would need to take their first steps online - the ability to make safe use of computers to access and communicate information.

Digital skills exist at a number of levels. The Interim Digital Britain Report identifies Digital Life Skills as one of three broad categories of digital skills, illustrated in Figure 1. These three skills areas overlap and share core competencies.

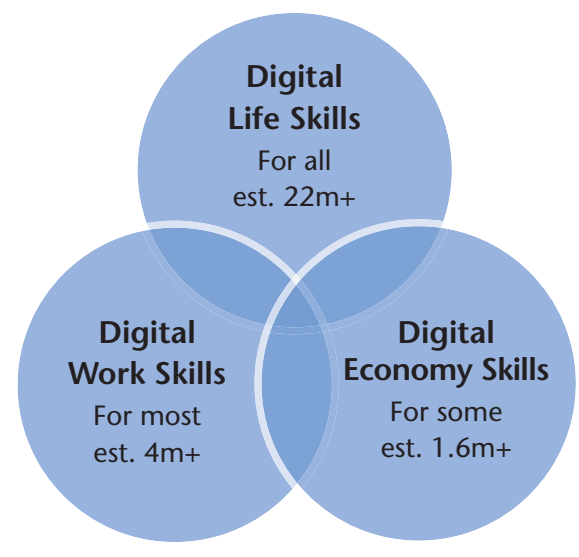

\section{Figure 1. Categories of digital skills}

This review only considers Digital Life Skills, as they are the foundation for the wider government plans for a 'Digital Britain'.

\section{Digital Life Skils definitions - in summary:}

- there are many terms used to describe the set of skills an adult requires to become digitally included.

- this review adopts the term 'Digital Life Skills' to identify a set of basic ICT skills an individual requires to use a computer to safely enter, access and communicate information online. 


\section{Section 4}

\section{The case for Digital Life Skills}

Investing in the ICT infrastructure of the nation and developing the skills of its citizens was a key government priority in 1997. Its aim was to increase the number of adults in the UK who 'communicate, interact and transact, using $I C T^{2}$. The rationale for investing public resources in extending ICT literacy was strong then and is even stronger now.

The review identifies five key reasons why all citizens can benefit from Digital Life Skills:

1. Social inclusion

2. Equality of access to information and services

3. Employability

4. Business productivity

5. Learning and skills

\section{Social inclusion}

Fifteen per cent of the adult population are both sociallya and digitally excluded ${ }^{b}$. Technology can help those at risk of social exclusion keep in touch with family and friends through email, participation in social networks, or internet telephony services, such as Skype. For those who are housebound or are unable to travel, it can provide much-needed social interaction and the chance to establish new friendships and support networks.

There are also significant benefits for elderly or vulnerable adults in using technology to provide access to medical services. 'Telecare' can help support these adults to continue to live independently in their own homes, through the use of equipment that makes it possible for them to call for help and assistance when they need it.

\section{Equality of access to information and services}

As more retailers and public services are using the internet to provide access to their products and services, adults who are digitally excluded risk being significantly disadvantaged. They are unable to access the time and cost savings of using the internet to shop, manage their finances, learn, and engage with public services.

a The Government's index of Multiple Deprivation defines individuals as socially excluded if they are subject to three or more forms of deprivation: income, employment, health, education (no qualifications), barriers to services, living (living alone).

b They lack digital skills and/or access to the internet. 


\section{"According to price comparison site uSwitch.com, the average saving generated using price comparison websites is 13\% for groceries, 15\% for travel and 21\% for services". 3}

Increasingly the internet is the medium of choice through which adults access a range of products and services; from renewing their car tax, to completing their self-assessment form or finding out more information about a family illness.

The Government's commitment for all secondary schools to put reports online on a child's attendance, behaviour and attainment, further underlines the importance of parents acquiring these digital skills.

\section{Employability}

Over the last 20 years, the proportion of people using IT in their job has nearly doubled to $77 \%$, with an estimated $22 \mathrm{~m}^{4}$ people using technology at work. For the remaining $6 \mathrm{~m}$ people in the workforce, these skills may not be critical for their employer but they remain important life skills.

Some employers advertise jobs solely online, and recruitment processes are increasingly electronic. More employers are making use of the latest web 2.0 technology to recruit employees, and increasingly employers are using or considering using e-learning, as a means to train employees.

Evidence from research by NRDC 5 shows a link between the development of Digital Life Skills and employability. Those people who are already digitally excluded are more likely to suffer unemployment in a time of recession. A lack of basic ICT skills will be a disadvantage in both finding and securing a new job.

A recent study by UK online ${ }^{6}$ focused on the differences between users and non-users of the internet in social class $\mathrm{C} 2 \mathrm{DE}$, and suggested a strong relationship between an individual's ability to use technology and their confidence in finding employment. Adults who were able to use ICT were $25 \%$ more confident about finding a job than non-users.

\section{Business productivity}

Employers are continuing to report gaps in ICT user skills amongst their employees. The 2007 National Employer Survey ${ }^{7}$ collected data from 79,000 employers with responses coming from businesses of all sizes and in all sectors of the economy. Twenty-four per cent of firms surveyed said their ICT user skills needed improving, with the need increasing with the size of business and $72.3 \%$ of businesses said they had increased training spend, or expanded training programmes, to address their skill gaps as they believed this had the potential to impact on productivity. 
The Office of National Statistics (ONS) has produced a number of studies linking internet access for employees with business productivity. A study into the manufacturing sector, found that on average companies experience a $2.9 \%$ increase in productivity for every $10 \%$ of employees who are given internet access ${ }^{8}$. In line with these findings, eSkills have suggested that through exploiting digital technology, small companies could "generate an additional £25bn of Gross Value Added (GVA) ${ }^{c}$ over the coming five to seven years"

\section{Learning and skills}

There is evidence which shows that when adults have a basic foundation of digital skills and the confidence to learn online they are more likely to stay engaged in learning and more likely to progress and achieve successfully.

\section{"Increasing access to broadband, open resources and digital services means there are more opportunities and media to support learning than ever before. Technology-enabled learning brings a sense of empowerment and wider choice to informal learning." (Becta, Harnessing Technology)}

A survey of FE learners conducted for Becta found "The majority of learners feel computers give them more flexibility (66\%), improve subject understanding (59\%) and lead to better performance in assessments (65\%)"11.

c GVA measures the contribution to the economy of each individual producer, industry or sector in the United Kingdom. 


\section{The case for Digital Life Skills - in summary}

- the review has identified five areas of policy where the Digital Life Skills agenda plays an important role: social inclusion; equality of access to information and services; employability and business productivity, and learning and skills.

- the digital divide is likely to increase if we do not help those adults who are digitally excluded to access the benefits that being online brings.

- Digital Life Skills have a key role to play in social inclusion, providing access for those who live alone or who are housebound to family, friends and vital healthcare services. Adults who are digitally excluded are unable to access the time and cost savings of using the internet to shop, manage their finances, learn, and engage with public services.

- an estimated $22 \mathrm{~m}$ people use technology at work $-77 \%$ of the working population.

- employers are increasingly using the internet to advertise, recruit and train employees.

- a lack of basic ICT skills will be a disadvantage in both finding and securing a new job.

- there is evidence to suggest a link between internet usage by employees and improved business productivity.

- a lack of basic ICT skills may hold people back from taking up learning and skills opportunities and from making progress to higher levels of learning. 


\section{Section 5}

\section{The story so far: government policy 1997-2009}

"The potential for ICT to transform society is well documented. Universal access to computers and the internet is considered necessary to avoid social divisions and offer opportunities for all by ensuring that future 'knowledge economies' include everyone." (HM Treasury 2000) 12

A review of government policy since 1997 shows a clear commitment from the Government to bring the benefits of technology to UK citizens.

In this section, we have identified the key initiatives that have arisen from government policy since 1997, which relate to the Digital Life Skills' agenda.

The first part of this section deals with government policies which are related to the Digital Life Skills agenda. The second section looks at the skills and education policies that relate directly to basic ICT standards and qualifications.

\section{7-2009 Government policy - digital agenda}

\begin{tabular}{|c|c|c|c|c|c|c|c|c|c|c|c|c|}
\hline 1997 & 1998 & 2000 & 2003 & 2004 & 2005 & 2005 & 2005 & 2006 & 2007 & 2008 & 2009 & 2009 \\
\hline Election & Learning & Knowledge & 21st & Enabling a & Inclusion & Connecting & Harnessing & Leitch & Delivering & Delivering & Digital & IAL White \\
\hline Manifesto & Age & Economy & $\begin{array}{l}\text { Century } \\
\text { Skills }\end{array}$ & $\begin{array}{l}\text { Digitally } \\
\text { UK }\end{array}$ & $\begin{array}{l}\text { Through } \\
\text { Innovation }\end{array}$ & $\begin{array}{l}\text { the UK } \\
\text { Economy }\end{array}$ & Technology & & $\begin{array}{l}\text { Social impact } \\
\text { through } \\
\text { technology }\end{array}$ & $\begin{array}{l}\text { Social } \\
\text { Inclusion } \\
\text { An Action } \\
\text { Plan }\end{array}$ & Britain & $\begin{array}{l}\text { paper } \\
\text { Britain }\end{array}$ \\
\hline
\end{tabular}

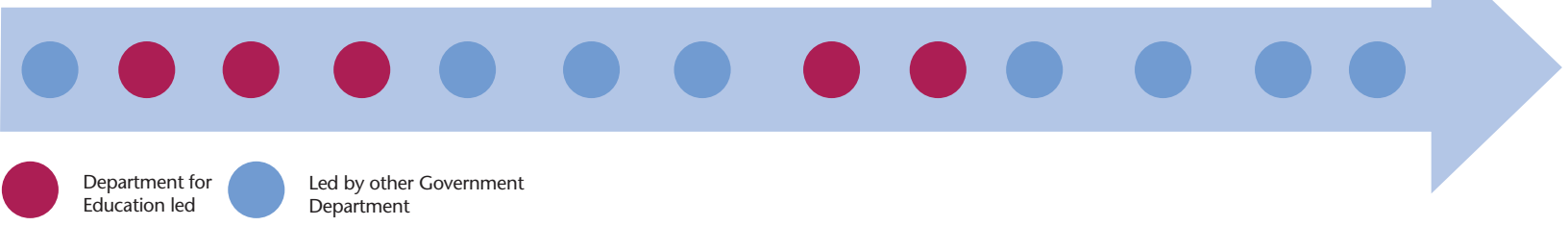

Figure 2. Key events: policy related to the digital agenda: 1997-present

In 1997, the Government implemented a number of initiatives aimed at providing internet access to $2 \mathrm{~m}$ adults by 2002 .

\section{Key policies}

a) In 1998, the Learning Age Green Paper ${ }^{13}$, set out the Government's vision for life, long learning and signalled the birth of University for Industry (Ufi) which was established in late 1999. Its objectives were to: 


\section{"provide a fast and responsive service in meeting the skill and business needs of employers, employees and of the self-employed, using leading edge technology to make learning available at work, in learning centres, in the community, and at home."}

b) In 2000, the Knowledge Economy White Paper was published. This provided $£ 1.7$ billion for a national IT strategy which included funding for schools, teacher training and infrastructure, including libraries. Key initiatives were:

- UK online: $£ 470 \mathrm{~m}$ of capital funding was allocated to establish a network of 1,000 centres providing access to technology, support to get online, and a nationwide promotional campaign. A target was set for 6,000 UK online centres by 2002. Centres are located across the most deprived wards in England and seven in 10 of the $2 \mathrm{~m}$ adults using UK online centres are affected by at least one indicator of social exclusion. Approximately $50 \%$ of users start with no formal qualifications.

- the myguide website ${ }^{\mathrm{d}}$ : this service offers an easy-to-use email service and websearch facility. Ufi took over the design, management and delivery of the project in 2004 and it was rolled out across UK online centres in May 2007. The service is now managed through UK online and by 1 March 2009, 132,000 people had registered on myguide and over 528,000 were using myguide courses. Eighty-four per cent of users say it has had a positive impact on their lives.

- the Wired-up Communities project ${ }^{14}$ : This initiative gave internet access to homes in disadvantaged areas and set out to establish whether computer access could transform an individual's access to work, training and leisure services. The $£ 10 \mathrm{~m}$ investment in 10 pilot schemes provided communities with a web portal with links to local services. The pilot was supported by a public-private partnership to give every household a computer. The scheme ran from 2000 to 2003 and realised significant benefits for those adults who took part.

- the Ufi network, under the learndirect brand, was expanded from 600 centres to 1,000 . The intention was that individual learners would be encouraged to move from taster and basic ICT courses, to more advanced ICT and other courses offered by learndirect.

- online IT introductory learning courses were made freely available for 50,000 adults, including the unemployed, the low paid, the disabled, and single parents, with a discount of $80 \%$ on fees for adults signing up for introductory ICT courses.

The 2000 White Paper also established the Office of e-Envoy which was charged with providing internet access for all who wanted it by 2005.

In early 2004, the Government established a Digital Inclusion Panel (DIP) by bringing together stakeholders from the public, private and voluntary sectors to identify the groups at the greatest risk of digital exclusion and to identify future actions to drive digital inclusion.

d http://www.myguide.gov.uk 
c) The 2004 Cabinet Office report, Enabling a digitally United Kingdom ${ }^{15}$, reflected the work of the DIP. The report:

- recommended a more joined up approach to the sharing of intelligence on digital engagement. Public services delivery through ICT would be identified through DirectGov and the new e-Government Unit.

- reinforced the importance of the UK online centres network in encouraging digital take-up across government services and engaging hard to reach communities. The report charged the Department for Education and Skills (DfES) with leading on improving ICT skills and overseeing access to public networks, but no further plans were put in place following this report.

- recommended more industry involvement to encourage digital take-up. It established an industry-led body, the Alliance for Digital Inclusion ${ }^{15}$, in conjunction with the charity Citizens Online. It also encouraged 'Intellect' to convene a new cross-industry, fully-representative group that focused on the implications of the convergence of broadcasting, telecommunications, broadband and the internet.

d) In 2005 the Social Inclusion Unit published Inclusion Through Innovation: Tackling Social Exclusion Through New Technologies ${ }^{16}$. This report led to the establishment of the Digital Inclusion Unit in England, funded by The Department of Communities and Local Government (DCLG). The key objective was to identify and evaluate good practice in tackling social exclusion through technology, and implement the recommendations. The report highlighted the importance of the third sector in providing access to socially excluded adults through advocacy, trusted brokerage, and alternative delivery.

Other recommendations related to the skills agenda including actions to improve the transparency of funding for the third sector; local authority promotion of UK online; the promotion of myguide across government; a call for the more effective use of data on social exclusion; and a metric in the form of a Digital Indicator to help measure progress of tackling digital inclusion. The metric has yet to be introduced.

e) Harnessing Technology ${ }^{11}$ was published by the DfES in 2005. It underlined the crucial role of digital skills in realising the wider skills needs of the economy.

f) In March 2005, the Government launched the Cabinet Office report, Connecting the UK: the Digital Strategy ${ }^{17}$ which included measures on internet safety and the embedding of ICT in education. Others related specifically to encouraging digital take-up by adults:

- the report emphasised the need to build on the network of UK online centres and other communal access points. 
- it announced the launch of the Computers for Pupils Programme, an initiative where local authorities are providing computers and connectivity for 100,000 pupils and their families in the most disadvantaged households in England.

- it announced the DCLG-sponsored Digital Challenge initiative. Its aim was to provide a national showcase for ICT innovation and set the vision required to create a truly digitally enabled society. Sunderland was announced as the overall winner. The 10 finalists formed the DC10plus ${ }^{\dagger}$ network who were awarded $£ 2$ million in March 2007 to drive forward initiatives proposed as part of the Digital Challenge. This group now works together to support other local authorities on projects focused on driving social inclusion through technology.

g) Commissioned in 2004 and published in 2006, the Leitch Review, Prosperity for all in the global economy - World Class Skills, ${ }^{18}$ examined the UK's long-term skills needs. Amongst other recommendations, the review set challenging targets for increasing skills amongst adults at all Levels. Skills for Life (SfL) skills were a key focus, but no specific targets were set for ICT SfL.

h) In 2006, the Government signed the Riga Ministerial Declaration. Governments committed to halve the gap in internet usage by 2010 for groups at risk of exclusion, such as older people, people with disabilities and the unemployed. There was no information available to the review about progress against this target.

i) An internal review of the Digital Strategy in 2007 recommended coordinated government leadership to address digital inclusion. This led to the establishment of a Digital Inclusion Minister and a Ministerial Committee in early 2008, supported by the Cross-Government Digital Inclusion Team.

The Digital Inclusion Team's Delivering Social Impact Through Technology ${ }^{19}$ report was published in 2007 . It sought to provide a framework for achieving greater digital inclusion and for championing the best use of technology to tackle ongoing social inequalities. It set out both immediate actions and a number of proposals for consultation. It made reference to other digital initiatives, including the pilot of Digital Mentors, announced in the DCLG report Communities in Control ${ }^{20}$. Digital Mentors will be recruited to work with people in deprived communities on projects which will help them to use technologies such as websites, podcasts and digital photography. Media Trust was awarded the contract in March 2009 to provide Digital Mentors.

j) A further DCLG report Digital Inclusion: An Analysis of Social Disadvantage and the Information Society, $2008^{21}$ explored the link between digital inclusion and social disadvantage. Its conclusions were that improving education could be a means to improving digital inclusion as well as improving access to technology and the quality of online services. 
k) Delivering Digital Inclusion, an Action Plan for Consultation ${ }^{22}$ was published in October 2008. The purpose behind the Digital Inclusion Action Plan was to ensure that all citizens, particularly those who are disadvantaged, were given the opportunity to realise both the direct and indirect benefits of digital technologies. The consultation period closed in January 2009 and The Ministerial Committee on Digital Inclusion (MISC34) is currently taking forward its recommendations.

The plan describes government involvement in over 70 actions across the public sector including a range of private and third sector initiatives such as: BT's Internet Ranger programme; Microsoft's Digital Literacy Curriculum; Citizens Online/BT's Everybody Online programme; Digital Unite's Silver Surfers' Day; Age Concern's Digital Inclusion Network and Silver Surfers' Week; Help the Aged's ICT taster courses; and AbilityNet's Switched On Communities programme.

I) The Interim Digital Britain Report ${ }^{1}$ was published in January 2009; the full report is to be published in June 2009. Its aim is to develop a strategy focused on achieving a fully digital Britain. The report will have specific chapters on Digital Participation and Digital Skills.

m) In March 2009, the Government published The Learning Revolution ${ }^{23}$, a White Paper on the future of informal adult learning. The paper puts forward recommendations to raise the profile of informal adult learning, improve access, and ensure sustainable provision. The White Paper makes particular reference to Digital Life Skills. Recommendations include:

- UK online to take on a stronger role in championing informal learning and supporting digital inclusion: hosting a range of new courses; offering space and support for self-organised learning; developing new partnerships with broadcasters and third sector organisations and providing a route to advice through the new adult advancement and careers service networks.

- DCSF to sponsor the development of a myguide course module to help people conduct effective web searches to find information about informal learning opportunities.

- Becta to develop, maintain and promote a directory of online resources for informal learning, to signpost people to all the great national and international resources.

- support for tutors in an informal adult learning context to develop their skills to use technology as a tool with which to deliver learning.

- ensure greater alignment of public funding for informal learning. DIUS will maintain its investment to secure a core offer in each local area through the £210m Adult Learner Safeguard Fund, but will enable local authorities to develop a stronger leadership role and better align this with other sources of funding. 


\section{3-2009 government policy - standards and qualifications}

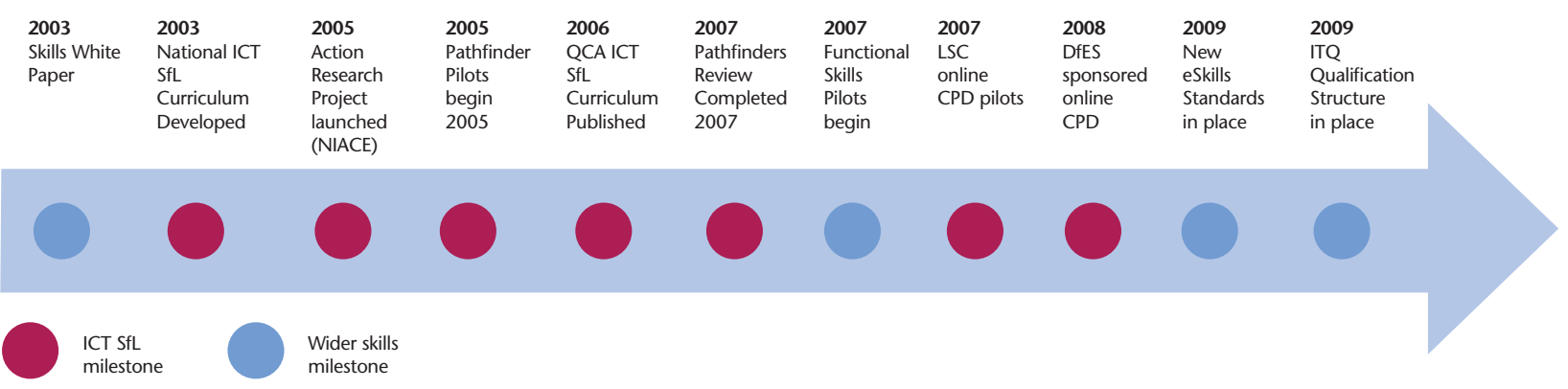

Figure 3. Key events: policy related to the Digital Agenda: 1997-present.

In 2003, the government White Paper 21st Century Skills Realising our potential ${ }^{24}$ recognised ICT as a Skills for Life (SfL) alongside literacy and numeracy.

\section{"The pervasiveness of ICT skills, both at work and for leisure purposes, means that functional competence in ICT needs to be counted as an essential skill for the modern world."}

A draft national ICT SfL curriculum was developed, and in 2005, NIACE led an action research project to look at the teaching and learning implications of the new standards. This work fed into a series of Pathfinder Projects ${ }^{26}$, to pilot the new ICT SfL qualification.

In 2006, the Core Curriculum document for ICT Skill for Life was published by the Qualifications and Curriculum Authority (QCA). The LSC undertook a review of funding for ICT User and Professional programmes, compared with other Humanities programmes. The review reduced the funding for all ICT User programmes, including ICT SfL. ICT SfL had never attracted the same levels of funding as literacy and numeracy, but this review further increased the disparity. ICT SfL now attracts $40 \%$ less funding than literacy and numeracy and, in addition, learners with ICT needs do not qualify for fee remission.

In 2007, a review of the Pathfinder Projects was completed. It showed the potential of ICT SfL to attract harder to reach learners by focusing on the development of their ICT skills in a purposeful and practical way. By 2007/08, the number of learners on ICT $\mathrm{SfL}$ programmes had reached just over 14,000. The successful evaluation of Continuous Professional Development (CPD) programmes in the pilot, led to an LSC, sponsored pilot of online CPD courses and continued investment in these by DIUS up to November 2008.

2007 saw the launch of the Functional Skills pilots, which will run until 2010. The standards reflect practical skills in English, ICT and Mathematics. The standards mirror those of ICT SfL at Entry Levels and are set to replace them, subject to pilot. 
Phased implementation of the Foundation Learning Tier (FLT) began in 2007/08. The FLT will provide learners with the opportunity to develop a personalised learning programme made up of units of learning at Entry Level and Level 1 of the Qualifications and Credit Framework (QCF) ${ }^{\text {g }}$. The intention is to motivate learners with few or no qualifications to engage in a programme which will provide the foundation from which they can progress onto further learning. The review of the National Vocational Qualification for IT Users (ITQ) has led to the development of the 'ITQ for Life' which represents an ICT progression pathway within FLT at Level 1.

A new ITQ User qualification framework was launched in January 2009. Developed by eSkills UK with input from employers, this framework allows IT User qualifications to be mapped into the National Occupational Standards (NOS) and given credit within the QCF, resulting in an ITQ qualification. In August 2009, a new ITQ Qualification Structure will be in place which will determine the units of qualification for IT user skills that will be accredited under the QCF.

g The QCF is a new way of recognising skills and qualifications. It does this by awarding credit for qualifications and units (small steps of learning). The QCF means that every unit and qualification in the framework now has a credit value and a Level between Entry Level and Level 8. Learners completing units can claim an award, certificate or diploma, depending on the number of units completed. (See Section 7 for more details.) 


\section{Government policy - in summary:}

- the Government's commitment to bringing the benefits of technology to UK citizens is evident in the range of digital policy papers and initiatives that have been put in place since 1997.

- there have been a number of successful initiatives such as learndirect, UK online and myguide which have helped large numbers of adults to improve their Digital Life Skills.

- the case for investing in digital inclusion is well documented but the range of initiatives across departments suggests they have not always been coordinated to best effect.

- there has been little focus in recent policy on the actions required to address gaps in adult Digital Life Skills and the implementation of policy as a result of the Leitch Review appears to have had unintended consequences for the take-up of Digital Life Skills.

- the 2003 announcement of ICT as a third SfL offered the opportunity for Digital Life Skills to become an important strand of the skills agenda. Despite the development of a curriculum and investment in good practice initiatives, the availability of the qualification has not resulted in a significant reduction in the number of adults digitally excluded, with only 14,000 learners registered on programmes leading to the qualification in 2007/08.

- $\quad$ recent skills policy on ICT has led to confusion on the part of providers and learners on what routes are available to them to develop their Digital Life Skills.

- the recent publication of the Government strategy on informal adult learning, and the forthcoming publication of the Digital Britain report present an opportunity for DIUS to lay out a clear strategy for the development of adult Digital Life Skills. 


\section{Section 6}

\section{Existing provision of Digital Life Skills}

\section{Providers}

An adult seeking advice on developing Digital Life Skills would find the current system difficult to navigate. A range of alternative providers offer a variety of courses which differ in length, delivery method and the commitment they require from the learner. In addition, the complexity of the funding system will make it hard for a learner to compare the real or opportunity cost of that provision. Making an informed choice in the current market is far from simple.

Providers who offer LSC funded programmes include Further Education Colleges (FE), Adult and Community Learning providers (ACL), University for Industry/learndirect (Ufi) and Work Based Learning providers (WBL).

In addition there are a number of alternative sources of training and support:

- through UK online centres (funded by government grant) providing free or low-cost provision to adults. Of their 6,000 centres:

- $47 \%$ are in public libraries - every public library in England

- $33 \%$ are in the Voluntary and Community sector (VCS) - including local community centres run by organisations such as Age Concern, MIND, and Foyer Federation

- $10 \%$ are in Adult or Further Education based venues

- $10 \%$ are in other organisations, including the private sector - ranging from pubs to private sector training providers

- through informal learning groups set up within communities.

- through commercial training providers, some of whom will also be WBL providers, many of whom provide training towards vendor qualifications such as Microsoft and Certiport.

- through commercial online vendors such as, Skillsoft, Cyclix, Mindleaders. These are usually bought by employers on a license basis and accessed through an employer's own learning portal.

- through publically available content such as BBC WebWise, which provides practical guidance to internet beginners and a series of online guides, attracting 94,000 UK users a week. $^{\text {h }}$ 


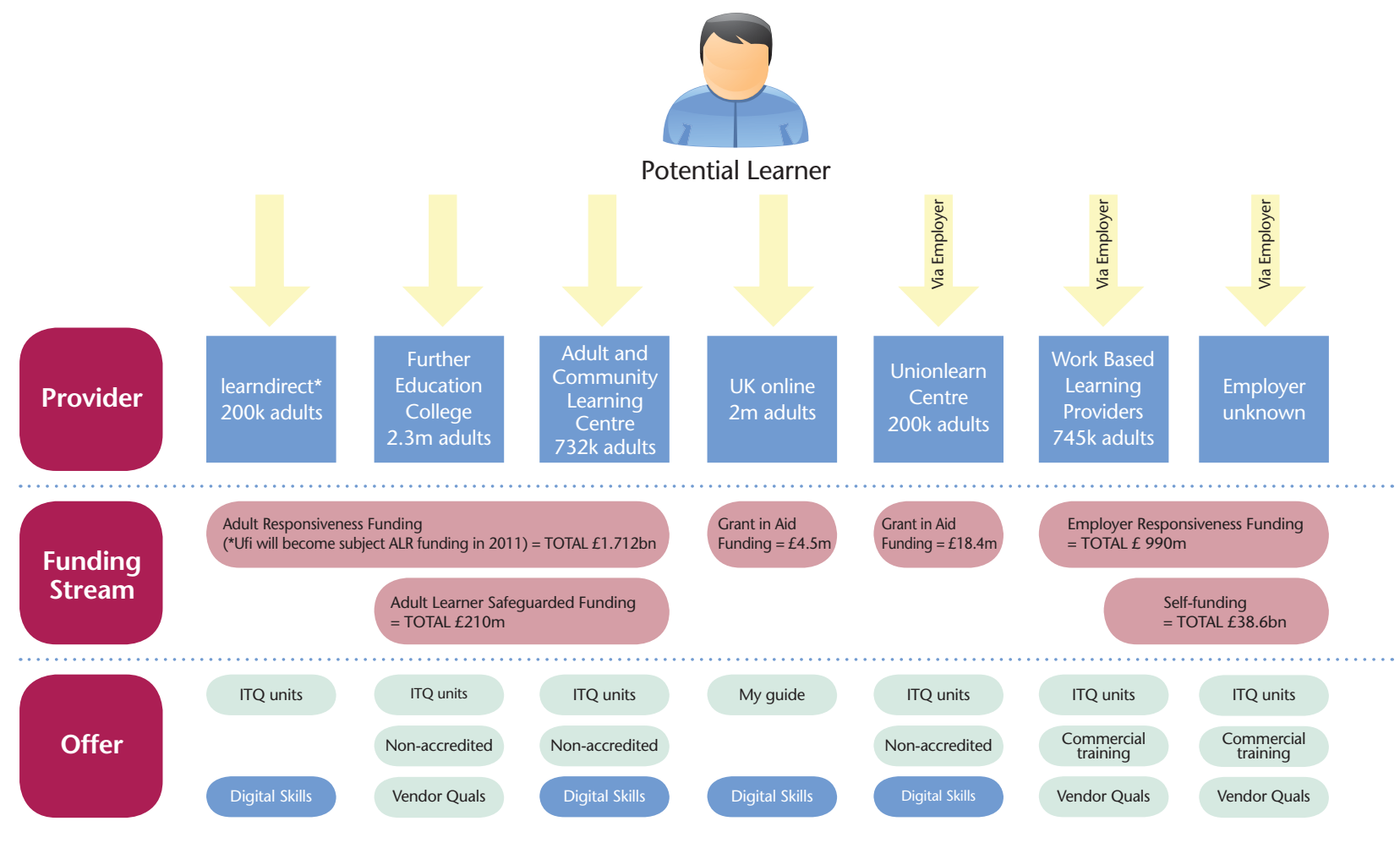

Figure 4. User choice of provision and funding route

Figure 4 illustrates the main categories of provider, how they are funded, and the core components of their offer.

\section{Trends in the volume of provision}

The Learning and Skills Council (LSC) is responsible for funding all adult skills provision. Since 2004/05, although the overall budget has increased, there has been a $23 \%$ decline in enrolments on LSC funded programmes as funding has been focused on longer, qualification-bearing courses.

A large proportion of this decline has been in ICT programmes. Data provided by the LSC Data Service suggests that over the same period there has been a $54 \%$ reduction in enrolments ${ }^{i}$ on ICT courses to just under 700,000 in 2007/08, and a 50\% reduction in learners to 485,000 learners in 2007/08.

FE and Ufi are the two funding streams where the majority of ICT learners have been lost. Figure 5 illustrates the number of learners on funded ICT programmes by provider in $2007 / 8$. There has been a $51 \%$ decrease in funded learners in FE, and a $73 \%$ decrease in Ufi. The $2 \%$ decrease in ICT learners in work-based learning has been offset by an increase in the number of learners on Train to Gain programmes. ACL has also seen a small increase, of $3 \%$.

As illustrated in Figure 6, 70\% of lost learners since 2004/05 have been at Entry Level and Level 1. 29\% have been at Level 2.

Note a learner may enrol on more than one course as part of a programme of study. 


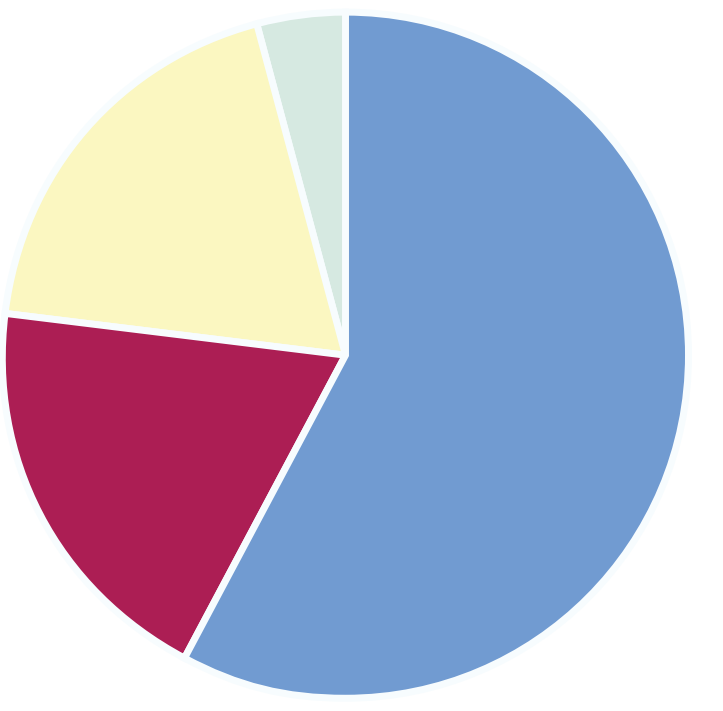

Adult learners on ICT Programmes by Funding Stream, 2007/08

FE - 405,700

Ufi - 134,400

$A C L-131,900$

WBL - 27,500

(includes Train to Gain)

Figure 5. Learners on ICT programmes

Source: LSC Data Service

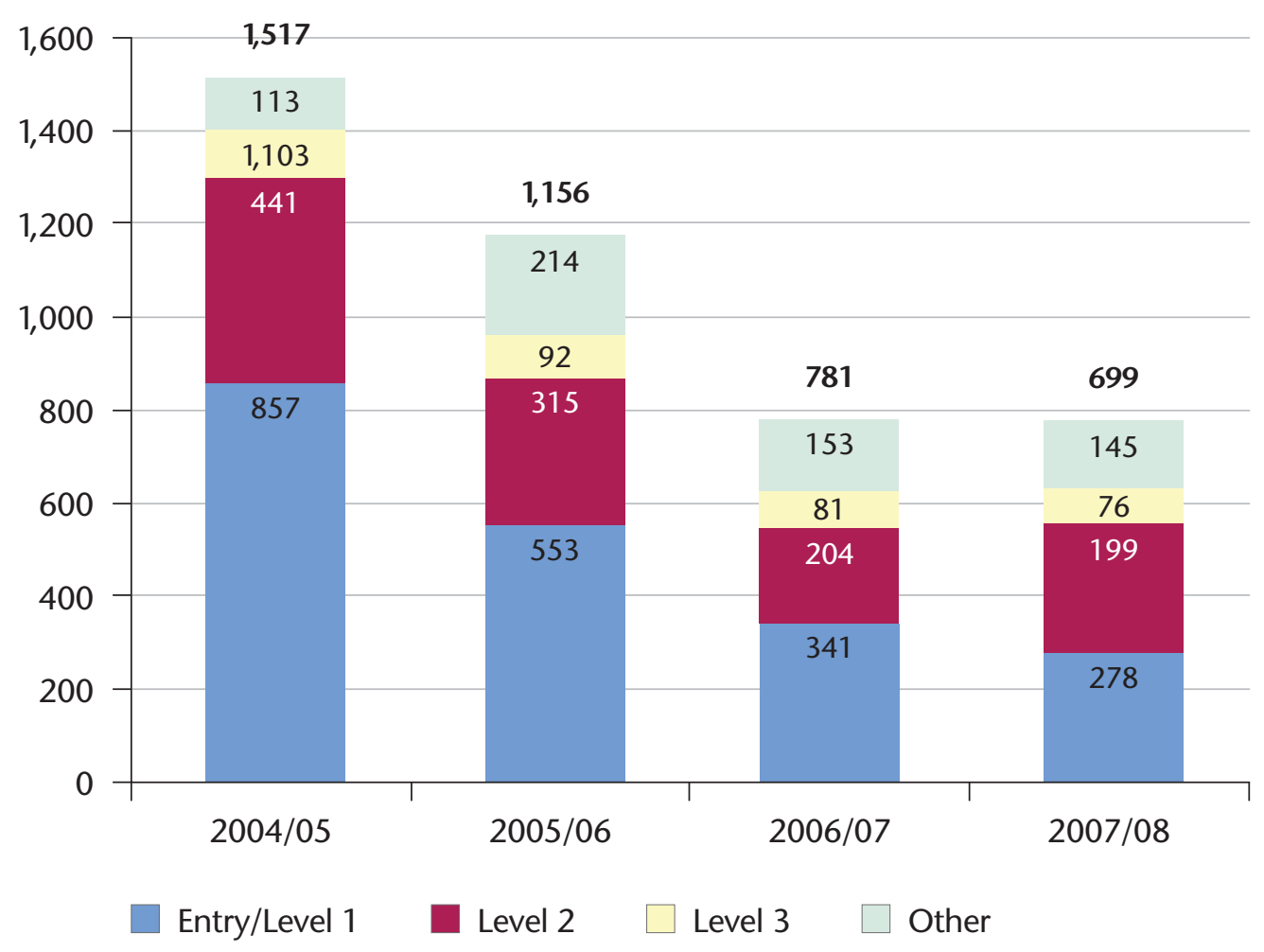

Figure 6. Funded enrolments on ICT programmes by Level, '000s Source: LSC Data Service 
The prioritisation of courses leading to literacy, numeracy and full Level 2 appears to have displaced ICT provision of less than 50 hours at Entry and Level 1 in FE. The majority of this provision (75\%) was accredited.

The removal of short courses (fewer than nine hours) accounts for the dramatic decline in Ufi provision which was designed to attract adults back into learning by offering short bite-sized units of learning. However, short courses account for only $10 \%$ of the total decline in FE.

There is no evidence to suggest that learners who were previously on funded programmes of less than 50 hours are now self-funding these programmes. The British Computer Society (BCS), who delivers ECDL qualifications in the UK, has seen a three-fold reduction in enrolments since 2004/05, including those which were previously self-funded. Success rates on ICT programmes remain one of the lowest across all subjects at $70 \%$.

The number of ICT qualifications has increased over the period with the introduction of NVQ, Diploma and Certificate programmes in 2004/05. Between 2004 and 2008, 261,458 qualifications were awarded for these new qualifications: 2\% at Entry Level, over $60 \%$ at Level 1, 34\% at Level 2 and the remainder at Level 3 and above.

It appears clear that those learners who were previously digitally excluded (no or low levels of exposure to ICT), and who could find a course prior to 2004, have not had the same access to basic ICT provision since 2005. The evidence suggests this is due to the removal of these courses by FE providers in favour of those which support government targets.

For Ufi a similar pattern emerges. Ufi learning providers have reduced their ICT offerings to learners and are now providing 'engagement' courses to approximately 30,000 of their 200,000 learners, to enable those learners to access the e-learning provision they provide.

UK online is continuing to provide $2 \mathrm{~m}$ adults a year with access to technology and support to develop digital literacy skills. Up to 500 of the 6,000 UK online centres receive grants for UK online each year but all are core funded through other routes.

The data suggests that motivated learners who are happy to complete a programme of study resulting in a qualification at Level 1 or 2 are increasing. The problem exists with those adult learners who are not motivated to learn towards a qualification, and where suitable provision which introduces them to the benefits of using Digital Life Skills through 'purposeful use' is required. This review suggests there are up to $13.9 \mathrm{~m}$ UK adults in this category, and $11.6 \mathrm{~m}$ in England. There is currently little incentive for FE to offer such courses, in terms of funding or targets. 


\section{Current sources of funding}

There are a number of budgets through which basic ICT skills are currently being funded. These are outlined below.

\section{Adult Learner Safeguard Funding}

This budget is designed to 'safeguard' learners' provision to adult learning. The providers contracted to deliver this stream of funding include local authorities, the Voluntary and Community Sector (VCS) and some colleges. There is currently $£ 210 \mathrm{~m}$ in the adult safeguard budget which is divided into four main streams of activity:

- Personal and Community Development Learning (PCDL), or leisure learning ( $£ 120 \mathrm{~m}$ and an additional $£ 35 \mathrm{~m}$ ring-fenced for colleges)

- Family Literacy, Language and Numeracy (FLLN), designed to help parents improve their skills in order to improve the prospects of their children $(£ 25 \mathrm{~m})$

- Wider Family Learning (WFL), funding for projects which engage adults in learning with a view to progressing them onto FLLN or Family Learning Impact Fund (FLIF £10m)

- Neighbourhood Learning in Deprived Communities (NLDP), funding voluntary and community projects $(£ 20 \mathrm{~m})$

In addition to the $£ 210 \mathrm{~m}$, there are two connected funding streams which flow through the same providers:

- FLIF, a more innovative fund aimed at life management in a family context - started in 2008, provided by DCSF

- First Steps, is designed to feed people into formal learning providing funding for learning tasters and initiatives such as Adult Learner Week $(£ 37.5 \mathrm{~m})$

Provision which closely matches that envisaged for Digital Life Skills appears within PCDL, NLDC, and First Steps. There are approximately 620,000 learners funded under adult learner safeguard provision, 100,000 of whom are on IT-related programmes at an approximate cost of $£ 33 \mathrm{~m}$ in $2007 / 08$.

\section{Adult Learner Responsiveness funding ( $\boldsymbol{R}$ LR)}

This is the main route through which FE and other providers are currently funded. Budgets for $2007 / 08$ totalled $£ 1.712$ bn which funded over $2.3 \mathrm{~m}$ adult learners. Budgets are agreed with providers by the LSC on an annual basis but funding is calculated based on the number of learners on courses and the expected duration of the courses - with adjustments made based on a providers success rate in getting learners to achieve their stated outcome (usually a qualification). Approximately $£ 317 \mathrm{~m}$ of the total ALR budget was spent on ICT programmes in 2007, with $20 \%$ of this being spent on Entry and Level 1 Programmes.

Within adult responsiveness funding there is currently a category called 'Developmental Learning' which relates to learning below Level 2 which is outside the national qualifications' framework. In 2008/09, 551,000 learners were expected to be funded 
through 'Developmental Learning' with the expectation that this would reduce to only 271,000 by $2009 / 10$ at a cost of $£ 230 \mathrm{~m}$.

\section{Grant in Aid funding}

Organisations such as Ufi and Unionlearn are currently Grant in Aid funded. Budgets are negotiated with the LSC on an annual basis in return for a set of outputs.

Unionlearn received $£ 18.4 \mathrm{~m}$ of DIUS funding in $2007 / 08$ which made up $65 \%$ of its income in that year. This money was used to support over 200,000 learners.

Ufi receives $£ 145 \mathrm{~m}$ a year in government funding. It is intended to move Ufi into the normal adult and employer funding arrangements by 2010, providing some budget protection up to 2011.

UK online receives up to $£ 4.5 \mathrm{~m}$ each year. $£ 3 \mathrm{~m}$ of this is spent on grants for centres, many of which support the development of Digital Life Skills. The remaining $£ 1.5 \mathrm{~m}$ funds the staff, content, tools and quality assurance system which ensures appropriate use of grants by centres. Over $£ 500 \mathrm{~m}$ has been invested by government and the Big Lottery Fund (formerly New Opportunities Fund) in UK online since 1999 - most of which was in the form of capital grants to build the network between 1999 and 2003. UK online has been identified as having a key role in the Digital Agenda in all government policy documents since 2003, yet funding of UK online has declined in real terms in recent years.

\section{Employer Responsiveness Funding (ERF)}

This is the channel through which Train to Gain is funded. In 2007/08 over $£ 990 \mathrm{~m}$ was budgeted for ERF, to support just under 750,000 learners. Contracts are awarded to providers, and different funding rates apply based on the programme outcome a learner signs up to. The focus of this funding is on NVQ delivery, primarily at Level 2 and 3 and literacy and numeracy qualifications. It is not currently possible to fund Digital Life Skills for employees through this budget.

\section{Self funding}

There is a significant amount of training which is paid for by employers through commercial suppliers. The 2007, the National Employer Survey suggested employers spent $£ 38$.6bn on training in 2006. It is hard to estimate how much of this is spent on ICT, but it is possible to conclude that ICT spend is focused mainly on application-based skills and professional ICT courses.

\section{Standards, qualifications and Digital Life Skills}

Once learners have determined where they can access provision, they will then need to make choices about whether they wish to work towards a qualification, and if so, which qualification will meet their needs. Increasingly, the only courses that are eligible for government funding are those which have a qualification outcome. The qualification system is a complex one, and there are currently a number of qualifications that have different titles but require a similar set of skills. 
Figure 7 shows the funded ICT User qualifications available to adults at the five lowest levels of the qualification framework from August 2009.

The lower half of Figure 7 shows skills at Entry Level. It is these that map most closely to Digital Life Skills. Employers will generally ask for a level of functional competence at Level 1 or above, so skills at this level map most closely to Digital Work Skills.

\begin{tabular}{|c|c|c|c|c|c|}
\hline L2 & & ICT Key Skill & $\begin{array}{l}\text { ICT Functional } \\
\text { Skills }\end{array}$ & \multirow{2}{*}{ ICT GCSE } & $\begin{array}{l}\text { ITQ Award, } \\
\text { Certificate, Diploma }\end{array}$ \\
\hline $\begin{array}{l}\text { L1/ } \\
\text { NC 4\&5 }\end{array}$ & & ICT Key Skill & $\begin{array}{l}\text { ICT Functional } \\
\text { Skills }\end{array}$ & & $\begin{array}{l}\text { ITQ for Life } \\
\text { (Includes Lit and num) }\end{array}$ \\
\hline $\begin{array}{l}\mathrm{EB} / \\
\mathrm{NC} 3\end{array}$ & Entry 3 ICT SfL & To be replaced by & $\begin{array}{l}\text { ICT Functional } \\
\text { Skills }\end{array}$ & & $\begin{array}{l}\text { Units at } \\
\text { Entry Level }\end{array}$ \\
\hline $\begin{array}{l}\text { E2/ } \\
\text { NC } 2\end{array}$ & Entry 2 ICT SfL & To be replaced by & $\begin{array}{l}\text { ICT Functional } \\
\text { Skills }\end{array}$ & & Units at Entry \\
\hline $\begin{array}{l}\text { E1/ } \\
\text { NC } 1\end{array}$ & Entry 1 ICT SfL & To be replaced by & $\begin{array}{l}\text { ICT Functional } \\
\text { Skills }\end{array}$ & & Level 1 and 2 \\
\hline
\end{tabular}

\section{Figure 7. The ICT qualifications landscape in 2009}

\section{ICI Functional Skills}

ICT Functional Skills are currently being piloted and it is the Government's intention to replace ICT SfL and ICT Key Skills with Functional Skills starting in 2010. Data suggests that there were just under 27,000 adults studying ICT Key Skills in 2006/0710 and 14,000 on ICT SfL programmes in 2007/08.

It is recognised that many of Functional Skills' assessments which are currently being piloted aimed at school-age learners and as timed computer-based tests, may not be attractive to Entry Level learners.

\section{ICT GCSE}

Take up from adult learners for ICT GCSE is very low with less than 1,000 learners taking programmes leading to this qualification in 2007/08. The new GCSE (first assessment 2012) will require learners to demonstrate ICT Functional Skills at Level 2.

\section{Vocational qualifications}

The recent review of vocational qualifications for ICT users by eSkills UK has led to the development of an ITQ framework. From August 2009, the current 292 funded Vocationally Related Qualifications (VRQs) will be grouped within the ITQ framework and linked to the achievement of an ITQ. This will reduce the options available to about 20 subjects and a total of 70-75 units. All awarding bodies will use this structure, so although awards such as CLAIT and ECDL will continue to exist, they will not be differentiated by curriculum standards but rather the service provided by those awarding bodies. In 2007/08, $70 \%$ of adult learners enrolled on ICT programmes were enrolled on VRQs, with over $40 \%$ enrolling on ECDL and CLAiT courses. 
The ITQ qualification structure will be based on common unit descriptions directly aligned to the National Occupational Standards for IT users, and all units and qualifications in the QCF will have a credit value.

The arrival of the ITQ for Life qualification provides a potential solution for learners wishing to progress from ICT SfL onto a Level 1 ICT qualification, and is intended for learners seeking employment skills as well as leisure learners. The ITQ for Life qualification is a recognised qualification pathway within the Foundation Learning Tier (FLT) and a Level 1 pathway within the ITQ framework

Currently it is not possible for a learner on a programme below Level 2 to be funded for units of qualification without enrolling on the whole qualification. The prospect of a 200-hour course may not be attractive to an adult learner who is often studying part-time. There is currently a trial of unit funding as part of QCF, but it is not clear if and when this might be available more widely.

\section{Vendor qualifications}

In addition to funded vocational qualifications, there are a number of vendor qualifications available in the market. These qualifications are popular with IT professionals at higher levels of the qualification framework. Both Microsoft and Certiport offer vendor qualifications at Entry, Level 1 and Level 2. Their awards have been linked to VRQs from City and Guilds (C\&G) and OCR.

\section{Delivery of Digital Life Skills}

Since Digital Life Skills does not currently exist as a discrete funded programme the review looked in particular at provision of ICT SfL programmes and found the following characterised current provision:

1. Effective provision is delivering ICT SfL in contexts that match the purpose for which the learner wishes to learn.

2. Teaching of basic ICT provision is not underpinned by a clear pedagogy, and existing programmes are delivered by tutors with a range of qualifications and backgrounds.

3. For some learners embedding ICT SfL provision in other learning, such as literacy, numeracy or vocational provision is an effective means of delivery.

\section{Learning for a purpose}

\section{"Good examples start with the learner and use the learner's purpose to teach the skills they need"26}

Traditional approaches to teaching ICT, focus on the knowledge and skills a learner needs to use computer applications. There is evidence to suggest that a large number of adults are still 'taught' ICT in a mechanistic way with an emphasis on didactic methods. It is widely accepted that this is one of the reasons for poor retention rates of adults on ICT programmes. 
The standards for Functional Skills and the qualifications these will replace, ICT SfL and Key Skills, require learners to demonstrate they can use ICT for a 'purpose'. The skills a learner requires for these qualifications are not application specific and are designed around a pedagogy of 'purposeful use'. This approach to delivery is believed to be the most effective for adult learners.

\section{Teachers and tutors}

NIACE have recently conducted a scoping study for Lifelong Learning UK (LLUK) to consider the roles and responsibilities of teachers who deliver ICT SfL. They have concluded that the generic professional standards for teachers, trainers and tutors provide an adequate description of their role, but that ICT teachers need more guidance on specific areas of their role including: developing appropriate teaching approaches and strategies; developing purposeful activities; keeping up to date with emerging technologies; and embedded approaches to delivery.

Evidence given to the review suggests that teachers of ICT SfL generally fall into two distinct groups: 1) teachers of literacy and numeracy and 2) teachers of ICT. Evidence suggests that teachers of literacy and numeracy are comfortable in teaching ICT SfL at Entry Level, but less so at Level 1 and 2; and ICT teachers are more comfortable at levels above Entry Level. They both adopt different approaches to the delivery of basic ICT.

The ICT SfL Pathfinders funded the development of Continuous Professional Development (CPD) courses and a portal through which teachers could exchange views, ideas and information. An evaluation of these CPD programmes ${ }^{27}$ suggests they have been well received by teachers.

It is clear that future policy will need to include CPD for a wide range of people involved in supporting the development of ICT and Digital Life Skills, including, teachers of other subjects, intermediaries, volunteers and digital mentors.

\section{Embedded delivery}

There is evidence to suggest that in delivering Digital Life Skills providers will also be presenting learners with opportunities to develop their literacy and numeracy skills.

\section{"IT user courses often attract low-skilled learners and could be used to help improve literacy and numeracy in a very accessible way. Suitably qualified teachers and tutors could maximise the benefits of the flexibility of the ITQ IT user qualification to recognise and address these needs"26}

The Microsoft Digital Literacy curriculum has been mapped to the SfL standards at Entry Level and found to cover $30 \%$ of the numeracy learning outcomes and $25 \%$ of those for literacy.

Embedded delivery, although it has many benefits, requires the learner and the teacher/ tutor to focus on the achievement of multiple competences. It therefore requires teachers/tutors to be skilled in both vocational delivery and ICT, and requires an element of self-direction by the learner. 
For some learners, including those who do not have literacy or numeracy needs, ICT skills may be more effectively delivered through a dedicated programme, where specialist teachers can be used. Through a dedicated programme learners can also be exposed to a range of other skills, including literacy and numeracy.

\section{Existing provision of Digital Life Skills - in summary:}

The choice of provision for an adult wishing to develop Digital Life Skills is complex and hard to navigate:

- $\quad$ funding for basic ICT provision currently comes through a variety of routes.

- $\quad$ since $2004 / 05$, enrolments on ICT programmes have reduced by $54 \%$ to just under 700,000 enrolments in $2007 / 08$, representing a $50 \%$ reduction in learners to 485,000 learners in $2007 / 08$.

- FE and Ufi are the two funding streams where learners have been lost, with $70 \%$ of learners lost at Entry Level and Level 1.

- the reductions in FE are largely due to the prioritisation by providers of courses leading to literacy, numeracy and full Level.

- the reductions in Ufi provision are due to the removal of funding for short courses (fewer than nine hours).

- the number of ICT Qualifications has increased since 2004/05 with the introduction of NVQ, Diploma and Certificate programmes.

- it appears clear that those learners who were previously digitally excluded (no or low levels of exposure to ICT), and who could find a course prior to 2004, have not had the same access to basic ICT provision since 2005.

- the standards and qualifications landscape that relates to Digital Life Skills is being rationalised for 2009 , but funding rules will not currently allow learners to access funding for small units of learning.

- teaching of basic ICT provision is not underpinned by a clear pedagogy, and existing programmes are delivered by tutors and learning support practioners with a range of qualifications and backgrounds.

- effective provision is delivering ICT SfL in contexts that matched the purpose for which the learner wishes to learn.

- for some learners, embedding ICT SfL provision in other learning, such as literacy, numeracy, or vocational provision is an effective means of delivery. 


\section{Section 1}

\section{Analysis of current policy}

There is no doubting the Government's commitment to the ICT agenda. In the last decade, significant progress has been made in improving the digital infrastructure and increasing the numbers of adults in the UK who are now online - from $8.1 \mathrm{~m}$ adults in 1999 to $33.4 \mathrm{~m}$ in 2008 . However, the ambition that all citizens should be ICT-literate is still a considerable challenge.

In considering how government policy should be reviewed, this report has reached the following conclusions:

1. The numbers of adults undertaking basic ICT courses has reduced. In the last four years there has been a $50 \%$ reduction in the numbers of adults enrolling on funded ICT programmes. The evidence suggests this decline has been largely due to the policy focus on qualification outcomes for Level 2, Literacy and Numeracy.

2. The qualification framework remains complex. There remains a bewildering range of formal programmes in which the focus on provision of basic ICT skills has been lost.

3. There is a link between digital exclusion and social exclusion. As we have shown in Section 6, although the total number of adults who are online has grown, the digital divide has deepened. Those who are socially excluded are at risk of further isolation as technology becomes an ever more integral feature of daily life.

4. There is a need to build on successful initiatives. There are some outstandingly successful initiatives, but not enough emphasis has been put on understanding the reasons behind their success and building on it.

5. There is a need for continued investment by government in infrastructure and skills in order to keep pace with changes in technology. In responding to this complex agenda, the government machinery addressing this area has itself become complicated and unwieldy. Different departments have different interests and, in order to coordinate government policy, a number of cross-departmental committees and structures have been developed. With the emergence of each new structure, previous decisions have been revisited. As a result, we lack a single focused strategy which will address the need for $11.6 \mathrm{~m}$ adults in England to acquire Digital Life Skills. 
This single focused strategy needs to be a priority for government if it is to achieve its aims of a truly digital Britain. Any such strategy should be developed in the light of the findings of this review. To this end, it must adopt the following principles:

- be easy to understand.

- be free from the wider qualifications framework.

- be led and managed by one government department.

- reflect an innovative approach to how, and by whom, it is provided.

- be flexible.

- use the best of the private and public sector.

- offer progression to those who choose it.

The following sections of this report identify the key features of this future strategy. In Section 8 we consider what we know our target audience, and in Section 9 we go on to propose a potential solution to the challenge we are faced with. 


\section{Section 8}

\section{Who are the digitally excluded?}

There has been little systematic evaluation of the Digital Life Skills of the UK population other than the Skills for Life Survey ${ }^{28}$, commissioned by the DfES in June 2002.

This review has used Office of National Statistics' (ONS) ${ }^{29}$ data as the basis for calculating the number of adults in the UK who are digitally literate, pre and post the 2003 survey. Data on the number of adults who have accessed the internet in the last three months is seen as the best available proxy for digital literacy.

\section{Digital skills in 2003}

The 2003 Skills for Life Survey put adults through assessments of literacy, numeracy and ICT. The ICT survey took 4,656 respondents aged 16-65 and gave them two ICT assessments. The first a test of awareness (of ICT technology and terminology); and the second a test of practical skills. The results suggested in 2003 over $21 \mathrm{~m}$ adults in Englandi had practical ICT skills at Entry Level or below; $15.2 \mathrm{~m}$ adults (38\%) had skills at Level 1; and only 3.6m (9\%) had skills at Level 2 or above. Those with skills at or above Level 2 tended to be younger, in work (with access to a computer), and have higher incomes.

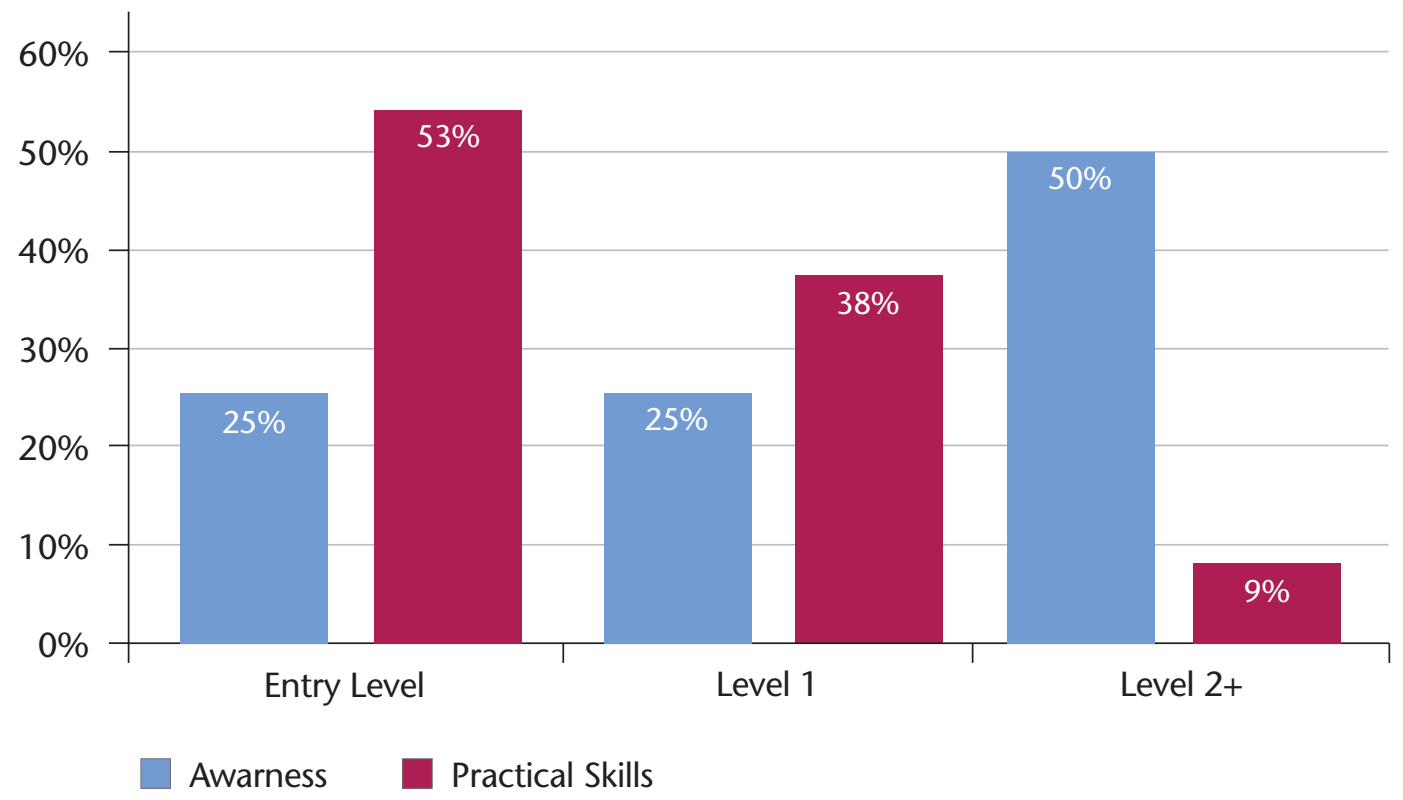

Figure 8. The level of ICT skills of adults (\% of total population), 2003 Source: SfL Survey 
A follow up to the Skills for Life survey has been commissioned by DIUS but will not report until 2011. The Organisation for Economic Cooperation and Development (OECD) has also set up the Programme for the International Assessment of Adult Competencies (PIACC) which will assess the level and distribution of adult skills across countries, including ICT Skills. Field testing is due to take place in 2010, with first tests in 2011.

\section{Digital skills in 2008}

Sixty-six per cent of all UK households now have internet access, and $94.1 \%$ of those are through a broadband connection ${ }^{28} .2008$ ONS data $^{k}$ suggests that $71 \%$ of adults in the UK have used the internet in the last three months, leaving $29 \% 13.9 \mathrm{~m}$ adults in the UK or $11.6 \mathrm{~m}$ in England who have not. An analysis of this data suggests the digitally excluded tend to be:

- older - over 65 s account for 7m (51\%) of those digitally excluded, yet make up only $20 \%$ of the adult population.

- socially excluded - often through unemployment, living in social housing, having low incomes or being single parents. $7.2 \mathrm{~m}$ (15\% of the UK adult population) are both digitally excluded and socially excluded.

- with few or no qualifications $-56 \%$ of the $3.8 \mathrm{~m}$ adults with no qualifications aged 19-64 in England are digitally excluded, this reduces to only $26 \%$ of the $5.5 \mathrm{~m}$ with qualifications below Level 2 , and only $7 \%$ of those $8.9 \mathrm{~m}$ adults with qualifications at Level 4 or above.

There are significant numbers of adults who are connected (live in a household with internet access) but who do not use it, they make up 30\% of those digitally excluded. Their decision may be based on a lack of motivation or skills and confidence in using ICT. Using data from UK online ${ }^{3}$ on the proportion of connected and disconnected users, it is possible to estimate that $4.3 \mathrm{~m}$ of UK non-users are connected and approximately $1 \mathrm{~m}$ of these are over 65 .

\section{Digital skills in 2021}

The effect on digital exclusion that can be predicted from population projections is shown in Figure 9. The age distribution of the 2006 population has been used to estimate the percentage of digital literacy by age group up to 2021. For this analysis we have assumed current levels of digital literacy by age group from the 2008 ONS data'. This suggests that, if all other factors remain constant, the overall proportion of the $16+$ population who are digitally excluded would reduce from $29 \%$ in 2009 to $15 \%$ in 2021, due to demographic change. In this scenario, by 2021 digital exclusion will continue to be a significant issue for those over 65 , with over $52 \%$ still experiencing digital exclusion.

\footnotetext{
Source: ONS 2008 data on internet usage by qualification and The Highest Level of Qualification held by adults, 2007, DIUS http://www.dcsf.gov.uk/rsgateway/DB/SFR/s000798/index.shtml

I This includes an assumption that $98 \%$ of the pre- 16 population are digitally literate, based on the findings of the third phase of the Becta review 'Under 16 internet usage: Young people and their context Survey Report, 2009'.
} 


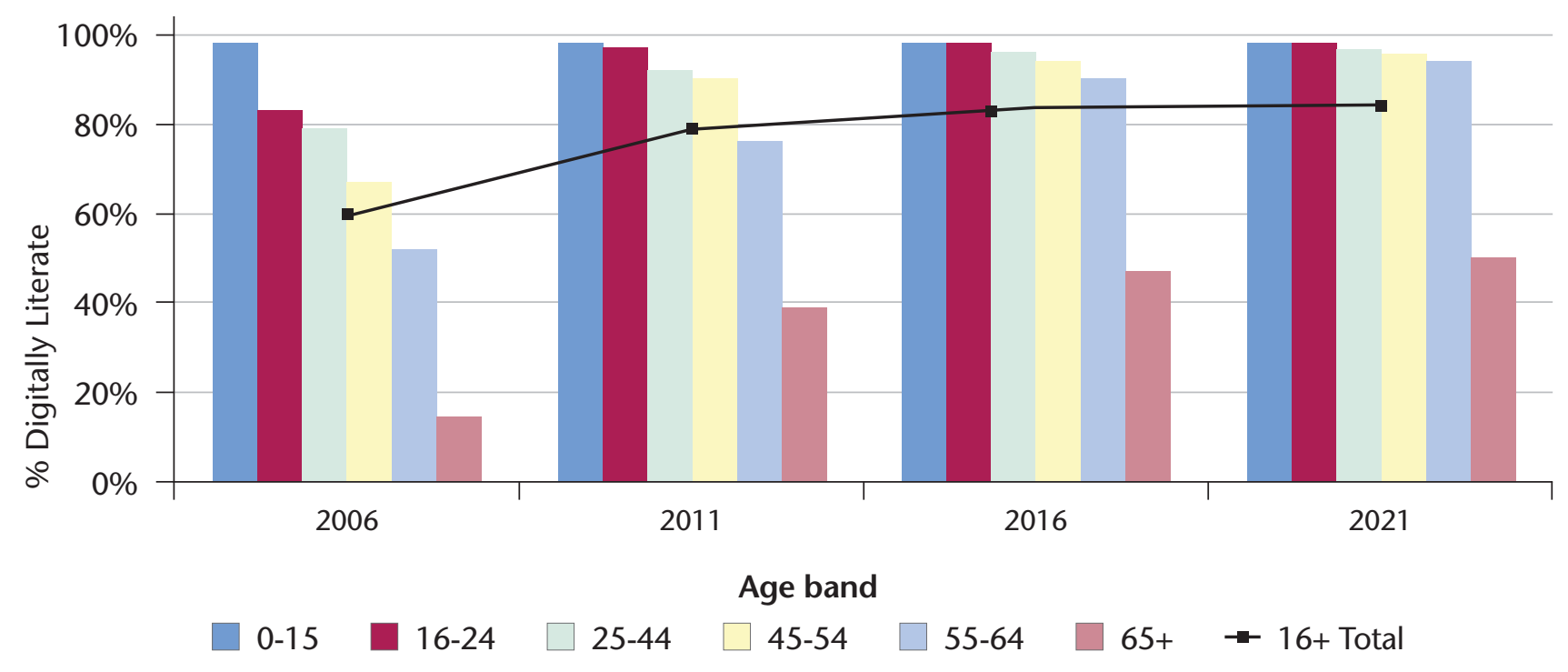

Figure 9. Digital literacy projections by age group up to 2021 Source: ONS Population Projections based on 2006 baseline. ONS, First release: internet Access 2008 and ICM \& UK online centres. Base: 7655 (weighted) ONS DIUS analysis.

\section{Attitudes to technology and learning digital skills}

$\mathrm{OfCom}^{30}$ have used data from their 2007 Media Literacy Audit to arrive at a segmentation of adults by their attitudes to technology. They label those who are 'not interested' as 'Resistors' and suggest $1 \mathrm{~m}$ adults in England (9\% of non-users) fall into this segment.

The research also involved interviews with 2,905 adults (16+) to establish their preference for learning about digital technology. Forty-eight per cent of the sample expressed a preference for learning from friends and family; $45 \%$ from reading the manual; $40 \%$ through trial and error; and only $6 \%$ from going to a class. Whilst it is hard to make conclusive judgements from one survey, such data does suggest that informal learning may have an increasingly important role to play in supporting the Digital Life Skills agenda.

UK online have taken this segmentation a step further, focusing specifically 'users' and 'non-users' adults in social groups C2DE. Their research suggests that a significant proportion of 'non-users' (45\%) are 'rejectors' who, although confident and happy in life, do not want to use the internet. The research found that their attitudes were rooted in views formed on the basis of negative media coverage, rather than direct experience. Of those 'users' surveyed, they found where people did use the internet it was for a specific purpose. 


\section{Who are the digitally excluded - in summary}

- $\quad$ Sixty-six per cent of all UK households now have internet access, and $94.1 \%$ of those are through a broadband connection. ${ }^{28}$

- $\quad 2008$ ONS data suggests there are $13.9 \mathrm{~m}$ adults in the UK, and $11.6 \mathrm{~m}$ in England who are digitally excluded. Those aged over 65, on low incomes, who are socially excluded, and with few or no qualifications are over represented in this group.

- Projections suggest generational change will mean that by $2021,15 \%$ of the population will be digitally excluded, as compared to $29 \%$ in 2009. Based on those projections 52\% of those over 65 will still be experiencing digital exclusion.

- Over $30 \%$ of those digitally excluded live in connected households.

- OfCom data suggests $9 \%$ of those digitally excluded are 'resistors' who are 'not interested' in being online. 


\section{Section 9}

\section{The way forward}

The challenge faced in helping $11.6 \mathrm{~m}$ adults in England gain the skills they need to take full advantage of the social and economic benefits of technology in the 21st Century, is a significant one. With the number of adults involved exceeding those of the combined numeracy and literacy targets set by Leitch, a specific strategy is clearly needed in order to avoid a situation where a digital divide exacerbates a social divide.

In Section 7, this review said that any strategy seeking to reduce the number of people who lack Digital Life Skills must:

- be easy to understand.

- be free from the wider qualifications framework.

- be led and managed by one government department.

- reflect an innovative approach to how, and by whom, it is provided.

- be flexible.

- use the best of the private and public sector.

- offer progression to those who choose it.

Moreover, in a difficult economic climate, where funding for skills development is limited, this review must focus on joining up existing policies and initiatives to increase the profile of Digital Life Skills' needs, and address them through a combination of national and local actions.

Rather than listing a range of policy actions, this review has focused on providing a simple, focused set of recommendations around the notion of an 'Entitlement' to Digital Life Skills. This Entitlement should provide an adult without Digital Life Skills with up to nine hours of funded support to develop the skills needed to get online. The Entitlement should be capable of being delivered in a flexible way, allowing progression according to the needs and wishes of the individual. This Entitlement would be for adults of all ages and all levels of education who do not have Digital Life Skills at a basic level.

Figure 10 illustrates how such an Entitlement might work in the current skills landscape. The recommendations outline what this Entitlement is, how it would be promoted, accessed, and provided to adults in England. The emphasis should be on giving adults one message, one point of contact; and coordinating provision through one body. The review recommends that the Department of Business, Innovation and Skills (BIS) should be made accountable for delivering this Entitlement alongside the existing skills SfL strategy. 


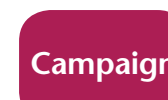

Single

point of

contact
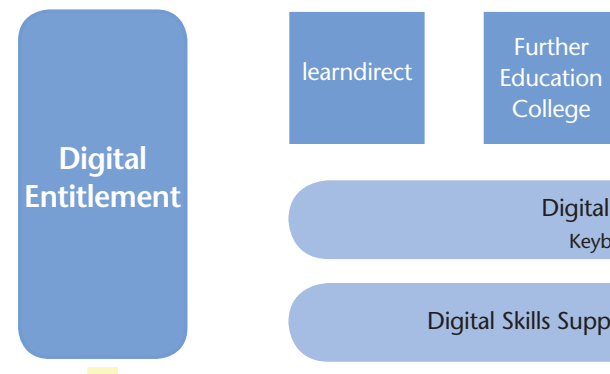

Further

Single phone Line and micro Site to signpost to provision (Directory of providers)

Do you have access to a computer? Where do you want to learn (Location)? What support do you need to learn? How do you want to learn?

Digital Skills Resource Bank Online Modules Links to additional Content Keyboard and mouse skills Using email Using the internet Keeping safe online

Digital Skills Support Teachers Tutors Learning Support Practitioners

\section{Figure 10. Digital Life Skills Entitlement}

\section{What would the Entitlement provide?}

The Entitlement would allow any adult without Digital Life Skills to claim up to nine hours of support to learn these skills from any provider involved in the scheme. This support would be funded by government through existing funding routes.

The Entitlement should consist of a core set of online learning modules which will support adults to:

- use a mouse and keyboard.

- use email.

- use the internet.

- keep safe online.

This review recommends building on the myguide service, developed under sponsorship from DCSF, to offer these modules. BIS should explore with DCSF whether the myguide service could be used in this way and what additional investment would be needed to facilitate this.

The content should be designed to require minimum support from tutors/teachers and will be freely accessible to both providers and learners. Both developments to myguide, and additional content available to support the Entitlement, should be developed through partnerships with broadcasters and sponsorship by commercial organisations. BIS should work with these partners to ensure the content is as attractive and effective as possible. 
What constitutes basic ICT is changing all the time as users find new uses for existing technology. The Entitlement would need to evolve over time to keep pace with technological developments.

\section{How will I be made aware of this Entitlement?}

The Entitlement would need to be promoted through a range of channels to encourage adults to take part. A social marketing programme, such as that proposed by the Digital Media Literacy Group, would be an effective means of launching and promoting the Entitlement.

This social marketing programme would draw on the existing activities of members of a consortium of public- and private-sector organisations including BBC, ITV, Channel 4, $B S k y B$, internet service providers, social media providers, UK online and NIACE, as illustrated in Figure 11.

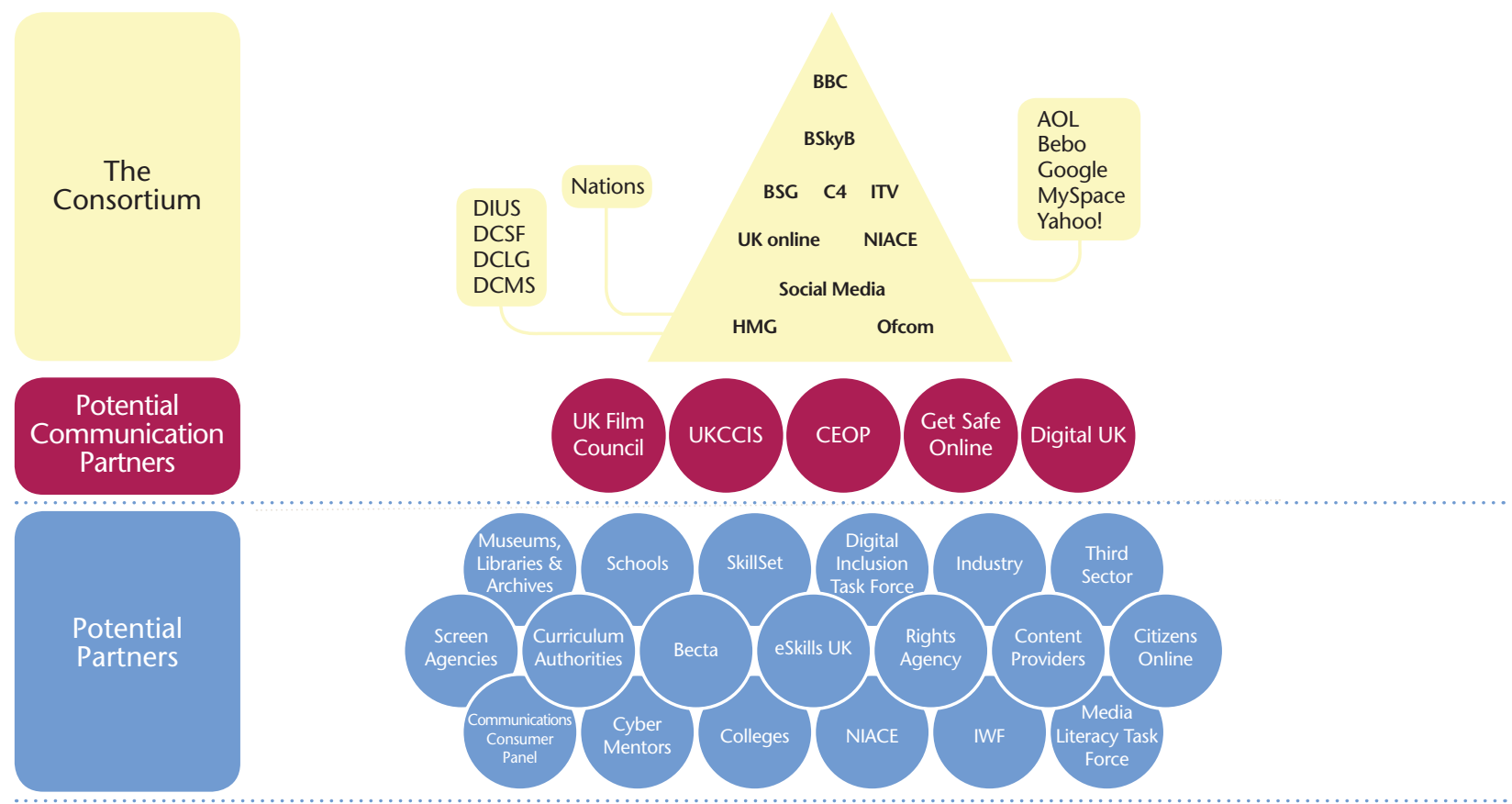

Members of the Consortium and how other stakeholders may align their activity to support the social marketing programme

Figure 11. Organisations supporting the proposed Social Marketing Programme Source: Report to Digital Britain - Digital Media Literacy Group, March 2009

The Entitlement needs to become a brand that people recognise and understand. It must articulate a compelling message about the benefits of being ICT literate in a modern society with an active democracy. Those messages might focus on: employability; access to information; convenient access to a greater range of products and services; cost or financial benefits; staying in touch with family and friends; or easy access to public services. The messages should be tailored to meet the needs of each target group, including those who currently see no benefit in learning ICT skills. 
Those adults who are the hardest to reach may only be accessed through the communities in which they live, or through the other services they use on a regular basis. Figure 12 illustrates the routes through which adults might be directed to the Entitlement. Examples of how this could be achieved include:

- the work of DCLG-sponsored Digital Mentors which may be one way of attracting adults to learn for a purpose, encouraging groups and communities to develop skills alongside digital community projects. Support for the Digital Mentor scheme has been reinforced in the IAL White Paper.

- for those who are recipients of state benefits, the process of claiming these benefits represents an opportunity for them to be made aware of the Entitlement and referred on to the single point of contact. For those adults who are unemployed and who are eligible for Employability Skills Training or Flexible New Deal there is no current requirement for providers to offer skills development in Digital Life Skills. Many providers use ICT to help applicants find information online and prepare applications, but this is not a mandatory requirement. This represents a missed opportunity to engage adults for whom these skills could lay the foundations of employability. BIS should discuss with DWP the promotion of the Entitlement to those adults claiming benefits and the introduction of a requirement for providers to deliver Digital Life Skills as part of the following programmes: Employability Skills for Jobs; Pathways to Work; and Flexible New Deal.

- the Government should ensure that the Home Access and the Computers for Pupils initiatives are also identifying and providing support to the parents/carers of the $1 \mathrm{~m}$ children these projects will reach. Evidence from the pilots suggests Home Access can have a positive impact on parents' skills and confidence in using $\mathrm{ICT}$, as well as those of their children. Becta are asking UK online centres to support adults as part of the pilot, and the Entitlement could be a means of providing continued funding for this support. BIS should evaluate the cost and impact of skills interventions with parents in the Home Access pilot, using this to inform future policy and funding in this area. The Adult Access initiative which is in 'proof of concept' has the potential to provide further evidence of the impact of reducing the 'access' barrier for adults, but is currently limited to those adult learners already in learning. BIS should consider whether the Adult Access initiative should be piloted more widely.

- as Skills Accounts are rolled out more widely, there should be opportunities for every adult learner without Digital Life Skills to be identified through the Careers Advisory Service (CAS). The LSC is currently in the process of commissioning a Skills Diagnostic Tool which will be used by the CAS to build a profile of an adult's skills needs. The Skills Diagnostic Tool will be accessible through the CAS website and will also be available to a range of advisers providing support to potential learners face to face, or at a distance. The focus of this tool has been on identifying learners with literacy and numeracy needs, but there is an opportunity to use the tool - and wider CAS service - to raise awareness of Digital Life Skills. The LSC will launch the Skills Diagnostic Tool from Autumn 2009. 


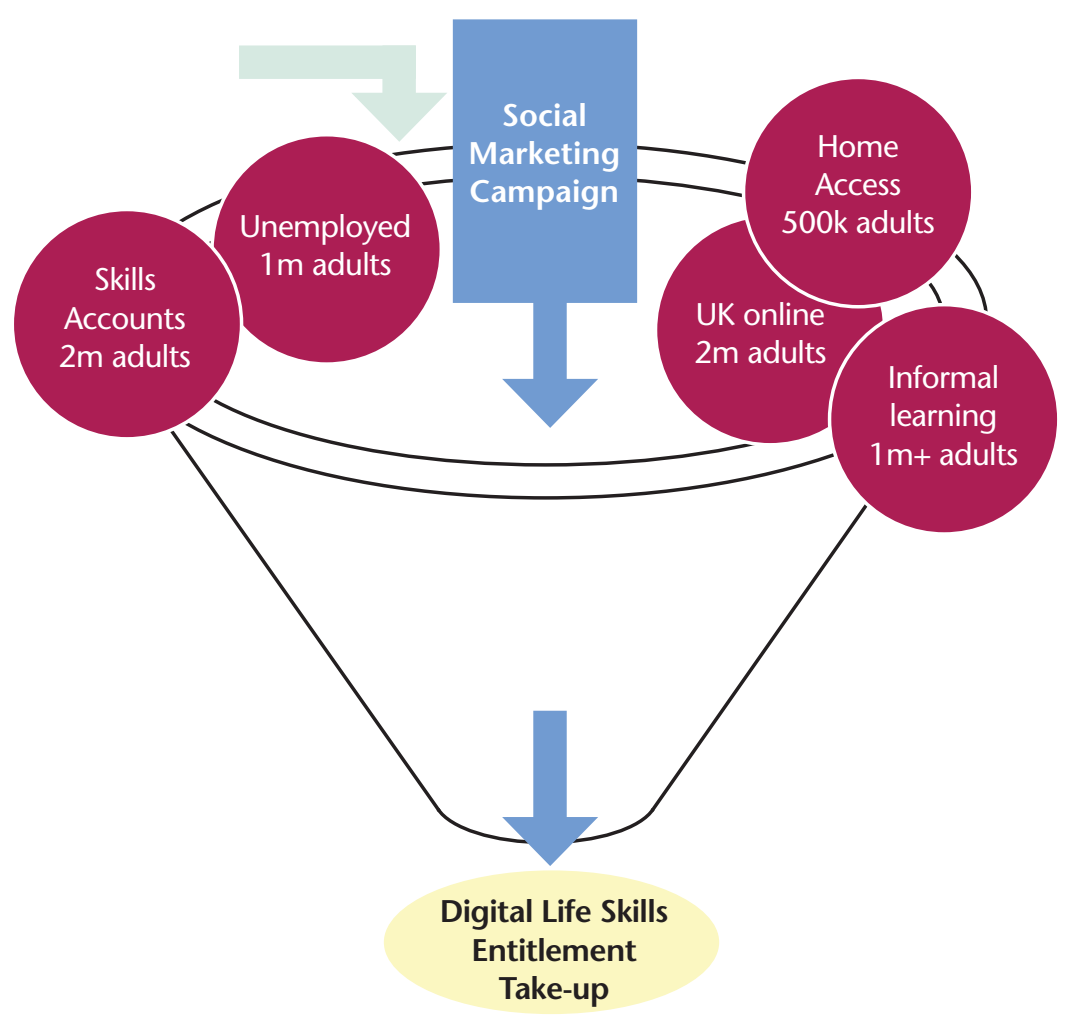

Figure 12. Channels through which to promote an Entitlement

\section{Where can I find out more about the Entitlement?}

The review suggests that adults responding to a call-to-action should be directed to a single phone line and website, where they can find out more about the Entitlement and get access to a Directory of Providers which lists where they can access it. Although the Entitlement should remain focused and uncomplicated, it should be possible for adults expressing the wish to be helped with wider needs to be transferred to the CAS for further support. BIS should discuss with the LSC, how the CAS could support any Digital Life Skills Entitlement.

\section{Where can I access the Entitlement?}

The Directory of Providers of the Entitlement should be broad-based and innovative in order to accommodate the different preferences adults have for learning about digital technologies.

For those adults who do not have access to a computer, but do not wish to attend formal provision, there are over 6,000 centres in England who are part of the UK online network; this includes all libraries.

Currently, 3,200 of the 6,000 centres are UK online 'member centres'. Member centres would play a key role in delivery, supporting adults to build the skills and confidence they require to become digitally literate. Local UK online centres also collaborate with outreach partners who can take equipment into other settings, eg, sheltered housing, housing associations. BIS should continue to support and fund UK online to play a major role in tackling the Digital Life Skills agenda. BIS and UK online should work to identify the cost 
of widening the membership network into all disadvantaged wards, and increasing the number of grants awarded to UK online centres to deliver the Entitlement.

In addition, other public access points would be available for those adults requiring minimal support. As well as existing internet cafés, these might be offered in partnership with commercial or public organisations such as:

- banks and retailers who have a vested interest in their customers being online.

- cafés and leisure areas.

- schools and colleges who, under the recommendations of the Informal Adult Learning review, will be encouraged to open up their spaces and facilities to their communities.

Adult and Community providers would also play an important role in delivering the Entitlement. BIS should establish a stream of activity within adult safeguard funding which is focused on providing an Entitlement to Digital Life Skills. In line with the review of informal adult learning announced in the 'Learning Revolution' White Paper, BIS could make Digital Life Skills a key strand of local authority provision. With the support of DCLG-sponsored advisers, the Digital Champion, the Digital Inclusion Unit and the use of the local authority benchmarking tool, local authorities could be encouraged to map Digital Life Skills provision at local level, ensuring provision meets the needs of their area.

The FE sector, Ufi/learndirect, and other providers funded through the adult learner responsiveness budget, can also play a role in delivering the Entitlement. This route would be particularly appropriate for those adults who had already made the decision to return to learn, and wished to develop their Digital Life Skills alongside other SfL or vocational provision. In addition those adults who have access to a Unionlearn centre through their employer, may access the Entitlement through this route. BIS should consider making funding for the Entitlement available through the adult learner responsiveness budget and charging Unionlearn with provision of the Entitlement through its centres.

\section{What support can I expect to receive?}

As well as providing access to a core set of online modules, funded providers would offer an adult the support of a tutor or learner support assistant, either face to face or at a distance/online.

There are many people who have the skills to support people in becoming ICT literate. There will be those who are qualified ICT teachers and will teach the entitlement in more formal settings, but we would expect a wide range of people to be involved in supporting the development of ICT - including teachers of other subjects, intermediaries, volunteers, and digital mentors. As part of the Entitlement, content would need to be provided that would support those assisting others to develop these skills.

The review has noted the particular needs of adults with disabilities. UK online have over 150 centres which specifically target and support people with cognitive or physical disabilities, and 90 centres which primarily deal with adults with mental health issues. 
For those adults who may be housebound or require specialist support in their homes - like those served by U Can Do IT - we recognise that providing an Entitlement will require ring-fenced investment through a dedicated budget, which is used to fund the specialist one-to-one support they will require to become digitally literate.

Content would be designed to be used by those supporting adults to develop the Digital Life Skills, as well providing resources directly targeted at independent adult learners with greater levels of confidence. Online content that can be used by providers delivering Digital Life Skills programmes is already freely available, through the ICT SfL website ${ }^{14}$, the Microsoft Digital Literacy Curriculum ${ }^{15}$ and BBC WebWise ${ }^{16}$. The availability of high-quality online content will reduce the need for specialist tutors to support learners on Digital Life Skills Entitlement programmes, allowing tutors within an informal learning setting to support learners to develop Digital Life Skills.

The Media Literacy Audit, conducted by OfCom in $2008^{32}$ suggests that $48 \%$ of adults would prefer to learn about digital technologies from friends and family rather than in a formal learning setting. It will therefore be important to provide the tools and resources that would allow a friend or family member to support a person to develop their skills. The BT Internet Rangers ${ }^{17}$ programme uses this approach, providing a website of downloadable tools and content for young people to help adults get online. BIS should encourage all commercial providers, and in particular those media and communication companies signed up to the Informal Adult Learning Pledge and Digital Consortium to make free content publically available.

\section{What will I get once I have demonstrated I have these skills?}

A certificate of completion will be available to adults completing the Entitlement. The Entitlement is not designed to be qualification bearing, but clear progression routes should be available for adults wishing to further develop their skills.

\section{How will I be able to progress having completed the Entitlement?}

Those adults wishing to progress should be able to access support and guidance from the CAS. BIS would provide clarity on progression routes for learners from Digital Life Skills courses into Functional Skills or Foundation Learning Tier (through the ITQ for Life), allowing credit for Digital Life Skills provision, subject to QCF pilots.

Following on from the announcement in the recent report Skills for life, Changing Lives $^{33}$, which signals the replacement of ICT SfL and ICT Key Skills with Functional Skills, a clear strategy should be put in place for general ICT qualifications from Entry Level to Level 2. This should be underpinned by one set of standards, but provide a range of appropriate assessment methods, including those suitable for adult learners.

Appropriate progression routes would include:

\footnotetext{
14 http://www.ictsfl.org.uk/

15 http://www.microsoft.com/about/corporatecitizenship/Citizenship/giving/programs/UP/digitalliteracy/default.mspx

$16 \mathrm{http}: / /$ www.bbc.co.uk/webwise/

17 http://www.btinternetrangers.co.uk/
} 
- ITQ: the introduction of the new ITQ framework offers the opportunity for learners to achieve units of qualification and build credit towards a qualification. If this is to be successful in stimulating demand from adult learners, and supply by providers, then funding will need to be attached to units of qualification.

- Functional Skills: only 500 of the 30,000 learners going through Functional Skills in the pilots are adults. This is being addressed in a second wave of pilot activity focused on adult learners. Currently the evaluation of this second wave pilot activity with adults is being limited to Literacy and Numeracy and will not include ICT. Evidence given to the review suggests there has been little attention given to the impact of a shift from ICT SfL to Functional Skills. BIS should ensure the Functional Skills pilots include an evaluation of the use of ICT Functional Skills with Entry Level adults, and that the findings are used to inform the development of appropriate assessments for adult learners.

\section{How will the number of people accessing the Entitlement be counted?}

The number of learners who access the Entitlement would be tracked through a simple online registration process which a user will be required to complete on accessing the service.

In addition, BIS would continue to track ONS data on digital inclusion as well as considering the results of two forthcoming surveys which should shed further light on the digital skills of adults in the UK:

- a follow-up to the 2003 Skills for Life survey has been commissioned by DIUS, but will not report until 2011.

- the OECD Programme for the International Assessment of Adult Competencies (PIAAC) will assess the level and distribution of adult skills across countries, focusing on the cognitive and workplace skills needed for successful participation in today's work environment. PIAAC will also gather data on participants' educational backgrounds and professional attainments, as well as their ability to use information and communications technology (ICT), and their general levels of literacy and numeracy. Field testing takes place in 2010 with first testing in 2011.

\section{In summary}

This review proposes a set of recommendations centred on the notion of an Entitlement to Digital Life Skills. The Entitlement seeks to join up a number of existing policies and initiatives resulting in an innovative strategy which addresses fully the range and flexibility of delivery methods required to meet the needs of such a diverse group.

In putting the emphasis on giving adults one message; one point of contact; and coordinating provision through one body; it is hoped that the Entitlement will remove much of the confusion currently surrounding the ICT SfL agenda.

In the last decade, significant progress has been made in improving the digital infrastructure and increasing the number of adults who are online. The introduction of an Entitlement would be an important step in addressing the needs of the $11.6 \mathrm{~m}$ digitally excluded adults in England today. 


\section{Bibliography}

1 Interim Digital Britain Report, BERR and DCMS, January 2009

2 Understanding digital inclusion - A research summary, Freshminds, April 2007

3 Economic benefits of digital inclusion, building the evidence, UK online and Freshminds, April 2008

4 Digital Britain: Creating Skills for the Digital Economy, submission to Lord Carter by eSkills UK and Skillset, 2009

5 The Digital Divide: Computer Use, Basic Skills and Employment. A Comparative Study in Portland, USA and London, England, NRDC, Oct 2008

6 Does the internet improve lives?, UK online and Freshminds, March 2009

7 National Employer Skills Survey, 2007

8 IT and Telecoms Insights 2008: Competitiveness of the UK IT and Telecoms Sector, e-skills UK, 2008

9 IT and Telecoms Insights 2008: The Impact of ICT on UK Productivity, e-skillsUK/ Adroit Economics and Regeneris Consulting, 2008

10 Harnessing Technology: Transforming Learning and Children's Services, DfES, March 2005

11 The use of ICT in further education, GfK NOP Social Research on behalf of Becta, 2007

12 Britain and the Knowledge Economy. Speech by the Chancellor of the Exchequer to the Smith Institute in London, HM Treasury, 16 February 2000.

13 The Learning Age, DfEE, 1998

14 " $£ 15$ million computer boost for low income families to bridge the digital divide" Department for Education and Employment Press Release 1999/0477 (28/10/99)

15 Enabling a Digitally United Kingdom. A framework for Action. Cabinet Office, 2004

16 Inclusion Through Innovation: Tackling Social Exclusion Through New Technologies, Office of the Deputy Prime Minister, 2005

17 Connecting the UK: the Digital Strategy, Prime Ministers Strategy Unit/DTI, 2005 
${ }^{18}$ Leitch Review of Skills (Leitch), Prosperity for all in the global economy world class skills, HM Treasury, 2006

19 The Digital Inclusion Landscape in England: Delivering Social Impact through Information and Communications Technology, Digital Inclusion Team, 2007

${ }^{20}$ Communities in control: real people, real power, DCLG, 2008

21 Digital Inclusion: An Analysis of Social Disadvantage and the Information Society, DCLG, 2008

22 Delivering Digital Inclusion: An Action Plan for Consultation, HM Government, 2008,

${ }^{23}$ The Learning Revolution: Informal Adult Learning White Paper, HM Government, 2009

24 21st Century Skills - Realising Our Potential: Individuals, Employers, Nation, DfES, 2003

${ }^{25}$ Getting on in Business, Getting on at Work, HM Government, 2005

${ }^{26}$ ICT Skills for Life, Pathfinder Project Report, 2007

27 Impact analysis of the ICT Skill for Life CPD programme upon the use of ICT in the curriculum, P Robinson and J Hammond, 2008

28 The Skills for Life survey: A national needs and impact survey of literacy, numeracy and ICT skills, DfES Research Brief RB490, 2003

29 Internet Access 2008: Households and Individuals, ONS, 2008

30 Digital Lifestyles, Heistants, Resistors, and Economisers, Ofcom, 2009

31 Report of the Digital Britain Media Literacy Working Group, 2009

32 Media Literacy Audit, Ofcom, 2008

33 Skills for Life: Changing Lives, DIUS, 2009 
Printed in the UK on recycled paper with a minimum HMSO score of 75

First published June 2009

Department for Business, Innovation and Skills

www.bis.gov.uk

URN 230-09-SK-b

(C) Crown Copyright

\section{5\% recycled Crecycle}

